This is the peer reviewed version of the following article:

"Recent Advances in Iridium(I) Catalysis towards Directed Hydrogen Isotope Exchange", W. J. Kerr, G. J. Knox, and L. C. Paterson, J. Labelled Compd. Radiopharm., 2019, doi: 10.1002/jlcr.3812;

which has been published in final form at doi.org/10.1002/jlcr.3812. This article may be used for non-commercial purposes in accordance with Wiley Terms and Conditions for Use of SelfArchived Versions. 


\title{
Recent Advances in Iridium(I) Catalysis towards Directed Hydrogen Isotope Exchange
}

\author{
William J. Kerr, ${ }^{a^{*}}$ Gary J. Knox, ${ }^{a}$ and Laura C. Paterson ${ }^{a}$
}

The initial discovery and establishment of a family of novel iridium catalysts possessing $\mathbf{N}$-heterocyclic carbene units alongside bulky phosphine ligands allowed selected substrates to be labelled using deuterium or tritium gas at desirably low catalyst loadings via an ortho-directed C-H insertion process. Such a method has broad applicability and offers distinct advantages within the pharmaceutical industry, directly facilitating the ability to carefully monitor a potential drug molecule's biological fate. Over the past decade since these initial protocols were divulged, many additional advances have been made in terms of catalyst design and substrate scope. This review describes the broadened array of new iridium catalysts and associated protocols for direct and selective $\mathrm{C}-\mathrm{H}$ activation and hydrogen isotope insertion within a number of new chemical entities of direct relevance to the pharmaceutical industry.

Keywords: hydrogen isotope exchange; $N$-heterocyclic carbene; deuteration; tritiation; iridium.

\section{INTRODUCTION}

Despite vast financial commitment to drug discovery, the global pharmaceutical industry faces significant attrition rates of drug candidate molecules in preclinical trials. Relating to this, early metabolism studies are central to addressing these prominent issues. A method of considerable importance in this arena is labelling by hydrogen isotope exchange (HIE), ${ }^{1}$ which directly facilitates the careful monitoring of a potential drug molecule's biological fate. The exchange of hydrogen in a $\mathrm{C}-\mathrm{H}$ bond by deuterium or tritium through directing group assisted ortho-HIE represents a direct and economical method of generating isotopically-labelled molecules (Scheme 1)..$^{1,2}$

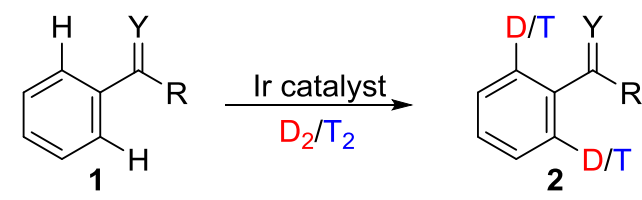

$Y$ and $R$ represent a range of functional units, including heteroatoms and ring systems

Scheme 1: ortho-Directed Hydrogen Isotope Exchange.

Due to the growing demand for deuterium- and tritium-labelled compounds for use in determining the pharmacokinetics of active pharmaceutical ingredients (APIs), and in mechanistic studies within the wider chemistry community, there has been increased focus on the development of catalysts capable of facilitating HIE in a mild, efficient, and selective manner. ${ }^{3}$ The literature in this area is well established with labelling techniques utilising a range of complexes of $\mathrm{Pt},{ }^{4} \mathrm{Rh},{ }^{5} \mathrm{Ru},{ }^{6}$ and $\mathrm{Ir}^{7}$ already disclosed. Having stated this, it is the complexes of iridium that have garnered considerable more recent attention. As related to this, processes with Ir have been historically performed using Crabtree's catalyst $3,{ }^{8}$ as first 
disclosed by Hesk and Heys. ${ }^{9}$ However, the necessity for a high, and often stoichiometric, catalyst loading when considering a wider range of substrates ${ }^{10}$ led to attention being turned to alternative and more specifically tuned catalyst species in recent years. In this regard, in 2008 our laboratory disclosed the use of novel iridium(I) carbene complexes of type 4 (Figure 1), ${ }^{11}$ which offered immediate advantages over Crabtree's catalyst in terms of catalyst efficiency and applicability, as well as a notable reduction in radioactive waste production resulting from tritiation experiments. ${ }^{11 b}$ Compounds $4 a-c$ (now commercialised by Strem Chemicals) are robust and readily handled materials, and, owning to the steric bulk and electronic balance of the $\mathrm{NHC} /$ phosphine combination, these complexes emerged as some of the most active species in the HIE domain at the time. An array of functional groups such as ketones, amides, and heterocyclic substrates were recognised as applicable with catalysts $4 a-$ c in ortho-directed hydrogen isotope exchange processes. ${ }^{11}$

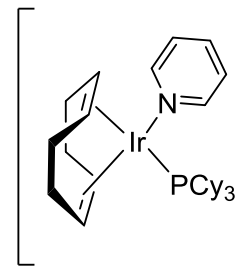

3

Crabtree
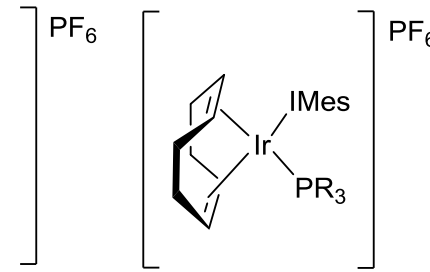

4a $\mathrm{R}=\mathrm{PBn}_{3}$

4b $\mathrm{R}=\mathrm{PPh}_{3}$

4c $\mathrm{R}=\mathrm{PMe}_{2} \mathrm{Ph}$

Kerr

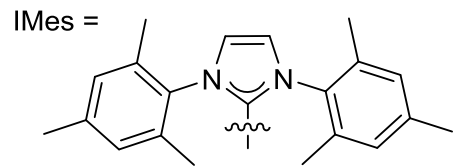

Figure 1: Iridium(I) Catalysts for HIE.

Following on from this work from our laboratory, this field of iridium catalysis has been further diversified over the last decade by combining knowledge on the synthesis and catalytic activities of developing iridium species, with a series of theoretical (DFT) studies informing catalyst design and driving the establishment of even more active, selective, and widely applicable HIE catalysts. This current review describes such recent advances in the development of iridium complexes as HIE catalysts and details the even wider array of organic substrates that can now undergo $\mathrm{C}-\mathrm{H}$ activation and hydrogen isotope exchange in an effective and selective fashion.

\section{ENHANCED SUBSTRATE AND SOLVENT APPLICABILITY}

In all initial protocols utilising the catalysts from our laboratory, the solvent employed had been dichloromethane (DCM), which, despite the efficiency that is evidenced using catalysts 4 , was deemed as a drawback to the established systems due to (i) the expected lack of applicability with all emerging drug-like substrates, and (ii) the associated hazards of chlorinated solvents, such as suspected carcinogenicity and high vaporisability. In a drive to replace this less industrially-acceptable solvent, and to media that may well allow more effective substrate solubility, following a detailed screening study, $t$-BuOMe, $\mathrm{Et}_{2} \mathrm{O}$, and 2-MeTHF all emerged as widely applicable labelling solvents for use with catalysts $4 a-c{ }^{12}$ Importantly, work within our laboratory also expanded the research studies at this stage to include a theoretical approach, which provided further insight and understanding in relation to these solvent-based investigations. Computational methods have shown that, of the solvents discussed above, 
DCM binds least well to the activated iridium metal centre. Furthermore, acetone, which was significantly less effective in labelling experiments of acetophenone, binds more strongly than the ethereal solvents. Importantly, we also calculated the binding enthalpies associated with the exchange of a solvent molecule with the substrate to be labelled, namely acetophenone, which concluded that the balance between solvent and substrate binding enthalpies is crucial in determining the ability of the labelling reaction to occur. More specifically, with DCM or the ethereal solvents listed above, the exchange of a solvent molecule by acetophenone is exothermic, whereas the same transformation with acetone occurs as part of a marginally endothermic process. ${ }^{12}$

An effective practical example of such solvent effects was revealed in the isotopic labelling of Bayer's anthelmintic, niclosamide 5 (Scheme 2). ${ }^{12}$ Employing catalyst $\mathbf{4 a}$ in DCM provided only moderate levels of labelling in each of the four positions at which exchange is expected, and with no significant site selectivity. However, the deuteration of 5 within 2-MeTHF delivered appreciably improved overall levels of labelling at a reduced catalyst loading. Such elevated labelling levels are proposed to be partially due to the higher solubility of niclosamide in the 2MeTHF solvent. Additionally, a clear preference for $\mathrm{H}-\mathrm{D}$ exchange through the more favourable 5-membered metallacyclic intermediate $(5-\mathrm{mmi})$ versus a $6-\mathrm{mmi}$ was noticeable in this ethereal medium. Such an example illustrates the importance of expanding applicable HIE solvent systems beyond DCM, and to include media which are compatible with more polar drug molecules.

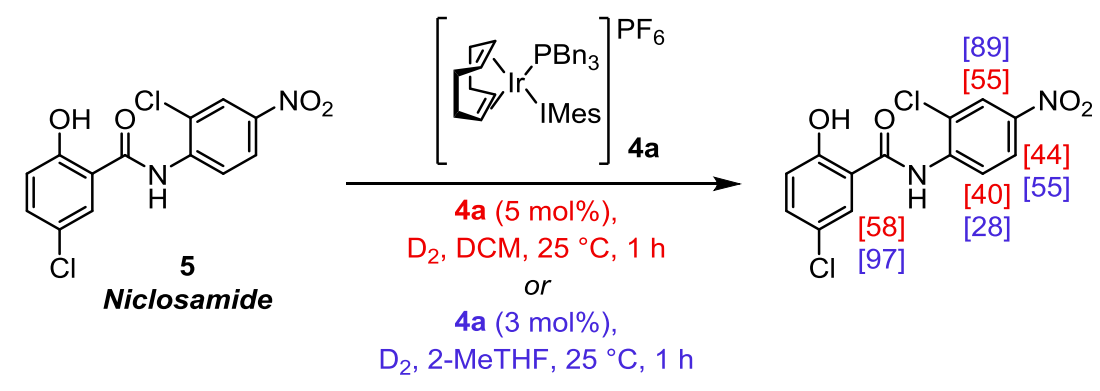

\section{Scheme 2: Solvent Effects in the Labelling of Niclosamide.}

In relation to substrate scope, further applicability of the catalysts emerging from our laboratory to a wider range of pharmaceutically-relevant heterocycles has been exemplified. Imidazole, oxazole, oxazoline, isoxazole, pyrimidine, and sulfur-containing thiazole substrates, as well as benzo-fused analogues, have been applied with very good levels of isotope incorporation under mild conditions and short reaction times. ${ }^{13}$ Illustrative examples are provided in Scheme 3. It is also worth noting that in this same study, alternative solvents $\mathrm{MeOH}$ and THF were applied in the labelling of drug-like heterocycles with beneficial effect. 


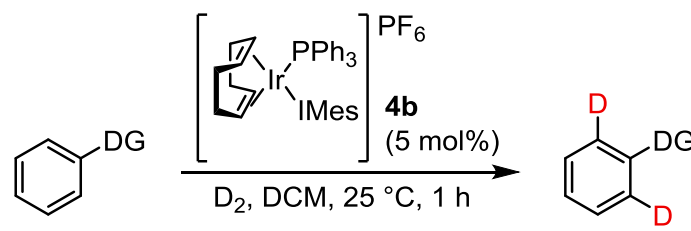<smiles>c1ccc(-c2ncccn2)cc1</smiles><smiles>c1ccc(-c2ncc[nH]2)cc1</smiles><smiles>c1ccc(-c2nc3ccccc3s2)cc1</smiles>

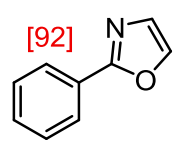<smiles>c1ccc(C2=NCCO2)cc1</smiles><smiles>c1ccc(-c2ccon2)cc1</smiles><smiles>Cc1cccc(COCCCOCc2coc(-c3ccccc3)n2)c1C(=O)O</smiles>

\section{Scheme 3: Labelling of Pharmaceutically-relevant Heterocycles.}

Further studies from our laboratory have gone on to establish the efficient, directed labelling of indole and pyrrole heterocycles, frameworks which, until recently, remained relatively underexplored classes of labelling substrates. ${ }^{14}$ Utilising common $N$-protecting groups to selectively direct $\mathrm{C}-\mathrm{H}$ activation, high levels of deuterium incorporation have been achieved for a range of substrates, including the industrially-relevant sumatriptan 6, a 5hydroxytryptamine-receptor drug (Scheme 4). 

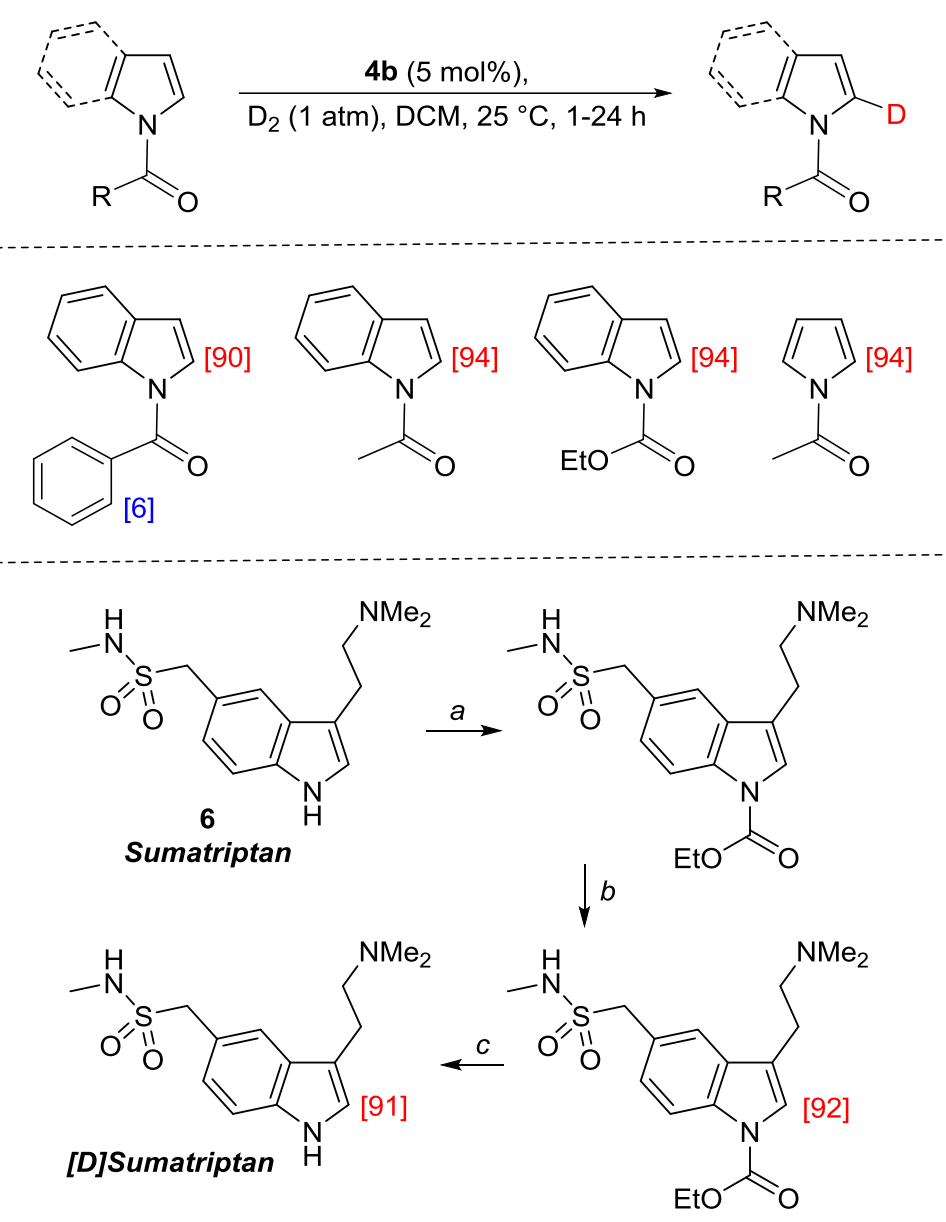

a) EtOCOCl, NaH, DCM, 53\%; b) 4b (5 mol\%), D 2 (1 atm), DCM, rt, $36 \mathrm{~h}$ $99 \%$; c) $\mathrm{NaOH}$, EtOH, r.t., 16 h, $87 \%$.

\section{Scheme 4: Directed Labelling of Indole and Pyrrole Heterocycles and Synthesis of [D]Sumatriptan.}

A more focused study has also been reported using catalysts of type $\mathbf{4}$ with the ester functionality, a directing group that had presented a far less robust profile when applying the previously optimised reaction conditions. Interestingly, it was found that performing reactions at a slightly elevated temperature of $40{ }^{\circ} \mathrm{C}$ significantly improved the levels of observed deuterium incorporation across a range of examples. ${ }^{15}$

In addition to the installation of isotopic labels on aromatic positions, we have also investigated the use of these catalyst species to introduce deuterium at non-aromatic $\mathrm{sp}^{2}$ centres and, specifically, at the $\beta$-position of $\alpha, \beta$-unsaturated systems (Scheme 5). ${ }^{16}$ Indeed, in order to label this class of substrates, careful consideration of the catalyst system was required in order to avoid competing alkene reduction. Fortunately, it was found that, the triphenylphosphinecontaining complex $\mathbf{4 b}$ was able to deliver excellent levels of incorporation, with high levels of selectivity using only $0.1 \mathrm{~mol} \%$ catalyst loading. 


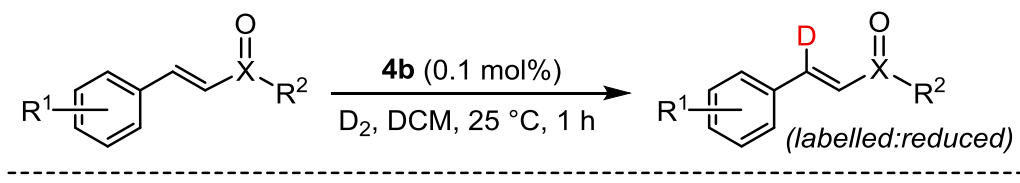

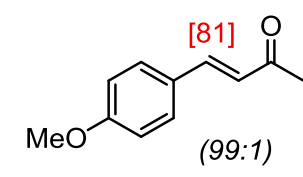

$\overbrace{(87: 13)}^{[93]}$

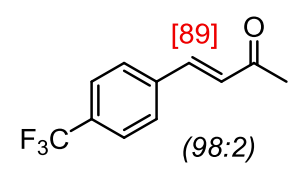

$\overbrace{(86: 4)}^{[84]} \mathrm{NEt}_{2}$

(96:4)

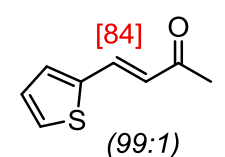

(99:1)

Scheme 5: Labelling of Non-aromatic Unsaturated Functionality.

\section{FURTHER ACCESS TO LABELLED DRUGS AND DRUG-LIKE COMPOUNDS}

In addition to the optimisation and application of the iridium(I) species 4 within our own laboratory, there have been several reports of others employing such systems in order to gain access to labelled drugs and drug-like compounds. One particularly notable example is the use of complex 4c by AstraZeneca isotope scientists in the synthesis of four tritiated drug molecules: $[T]$ ethylmelagatran, $[T]$ melagatran, $[T]$ ximelagatran, and $[T]$ hydroxymelagatran. ${ }^{17}$ Carbamate-protected amidine 7 was selected as an intermediate which could be successfully labelled (Scheme 6) and subsequently transformed into the desired tritiated targets in a further one or two step procedure. Whilst previous use of Crabtree's catalyst (in stoichiometric quantities) had yielded less satisfactory levels of specific activity and radiochemical purity, the use of complex 4c, at only $10 \mathrm{~mol} \%$ catalyst loading, furnished a sample of the labelled intermediate with appreciable levels of isotope incorporation and radiochemical purity, and beyond the minimal requirements of the study.

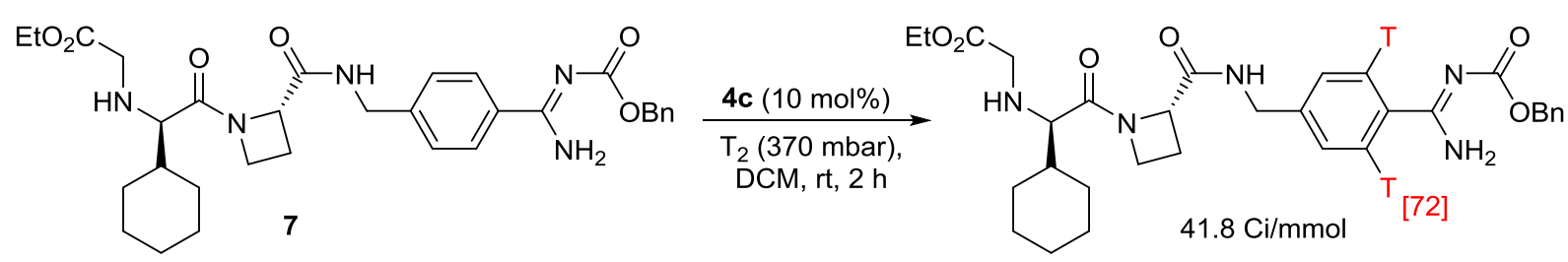

\section{Scheme 6: Tritiation of a Key AstraZeneca Drug Precursor.}

Another noteworthy example of the application of complex $\mathbf{4 c}$ is in the synthesis of tritiated AZD5248, a highly potent and selective cathepsin C inhibitor, which was required for preclinical metabolism studies. ${ }^{18}$ While direct labelling of AZD5248 proved challenging, due to the presence of the strongly coordinating nitrile groups within the final molecule, compound 8 was selected as a suitable precursor. Using the amide directing group, in conjunction with complex 4c, a sample of $\mathbf{9}$ was afforded with good levels of specific activity at $13.3 \mathrm{Ci} / \mathrm{mmol}$ (Scheme 7). This compound was then dehydrated by reaction with the Burgess reagent, followed by Boc deprotection by stirring in formic acid. This sequence successfully afforded the requisite radiolabelled sample of AZD5248. In addition, AstraZeneca-based researchers 
have showcased further applications of catalysts 4 in the attempted production of labelled drug molecules. $^{19}$

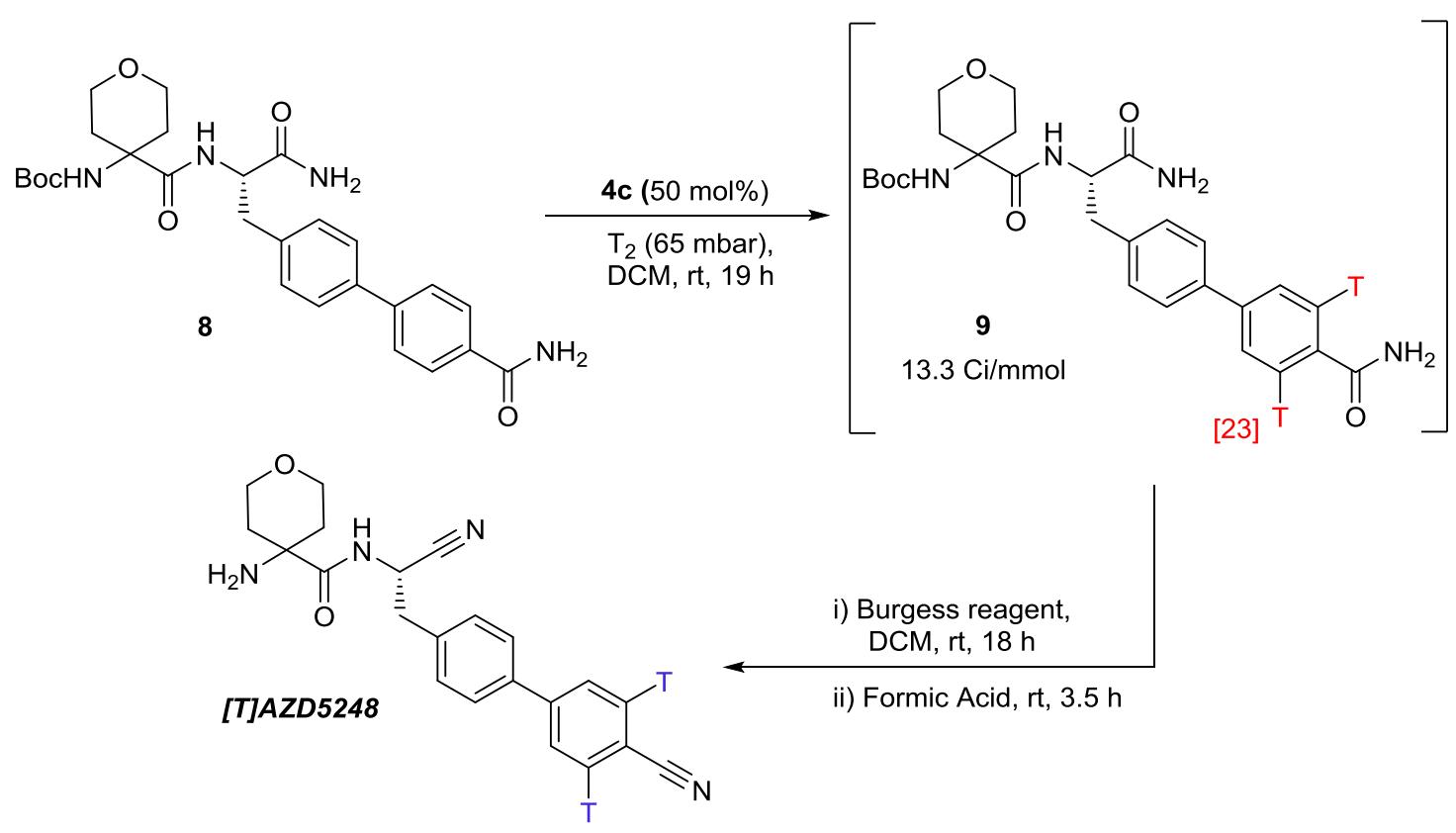

Scheme 7: Preparation of Tritiated AZD5248.

A further example of application of the catalyst system 4 comes from Skrydstrup and coworkers. $^{20}$ In this report, these researchers have disclosed a method for $\mathrm{sp}^{3}-\mathrm{sp}^{3}$ diboron compound reduction of $\mathrm{H}_{2} \mathrm{O}$ or $\mathrm{D}_{2} \mathrm{O}$ to produce hydrogen or deuterium gas, respectively, and for the resultant practically-convenient use of the in situ generated species within their twochamber reactor system. While this report described a number of examples of this technique in hydrogenation (and associated reduction processes), notable examples of HIE using catalyst 4b were also showcased. Using complex $\mathbf{4 b}$ at $5 \mathrm{~mol} \%$ loading, a selectively deuterated sample of olaparib (an ovarian cancer drug) was accessed directly (Scheme 8). ${ }^{20}$ In a similar and earlier approach with $\mathrm{Zn} / \mathrm{DCl} / \mathrm{D}_{2} \mathrm{O}$ in the Skrydstrup two chamber system to generate $D_{2}$ gas (at 3 bar), labelled CX-546 (a schizophrenia treatment) was obtained with good levels of isotope incorporation (Scheme 8). ${ }^{21}$ 

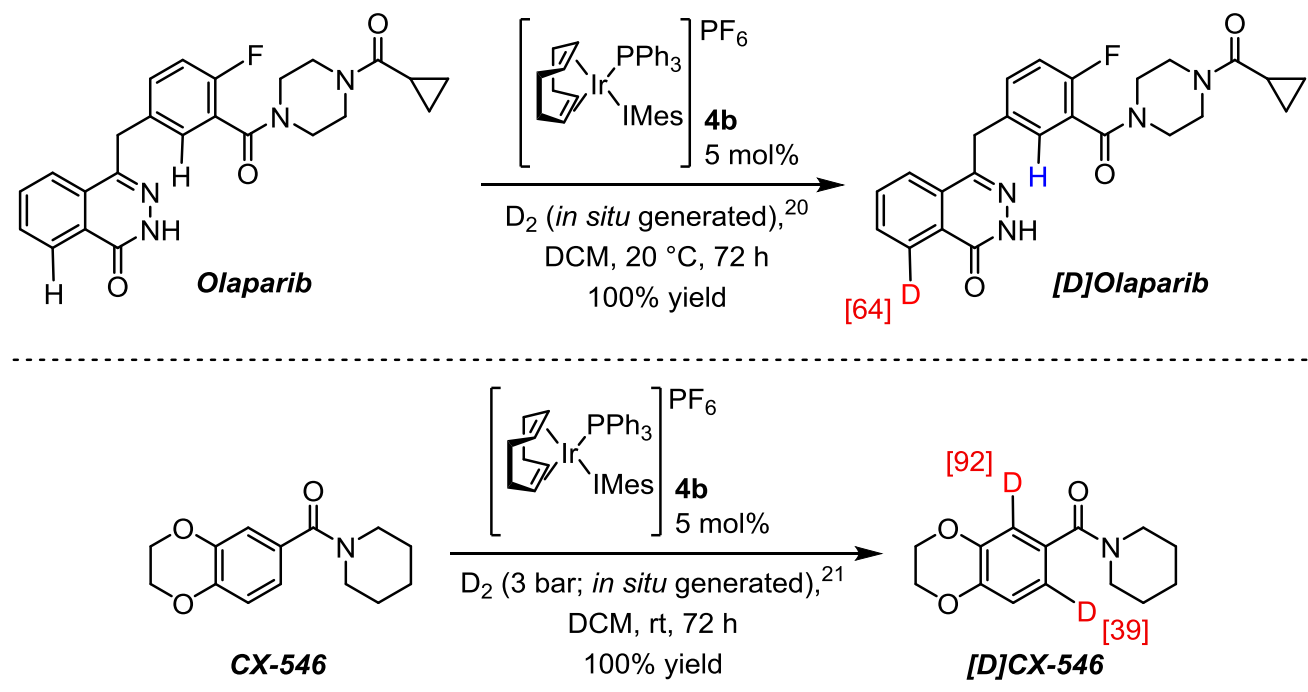

Scheme 8: HIE Using Skrydstrup's Two-chamber Reactor System.

\section{COUNTERION EFFECTS}

A key breakthrough in this area of directed hydrogen isotope exchange was the preparation and application of further, novel, cationic iridium $\mathrm{NHC} /$ phosphine complexes bearing alternative counterions to the traditional hexafluorophosphate $\left(\mathrm{PF}_{6}\right)$ ion present in our flagship catalysts $4 .^{22}$ The assessment of a range of counterions, both larger and smaller than $\mathrm{PF}_{6}$, showed that the relative efficiency of each catalyst increases in order of increasing counterion volume. Encouraged by research carried out by Pfaltz and others in iridium-based catalysis, ${ }^{23}$ studies performed within our laboratory noted improved catalyst applicability and efficiency with $\operatorname{Ir}(\mathrm{I}) \mathrm{NHC} /$ phosphine complexes of type 10, containing the particularly diffuse $\mathrm{BAr}_{\mathrm{F}}$ (tetrakis[3,5-bis(trifluoromethyl)phenyl]borate) counterion (Figure 2).
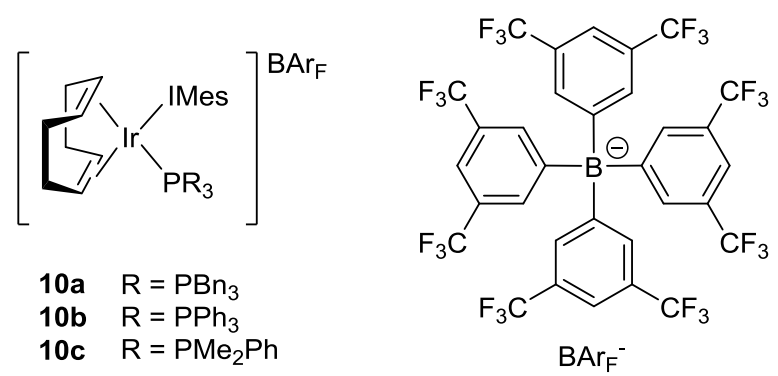

Figure 2: $\mathrm{BAr}_{\mathrm{F}}$ Complexes.

Moving to this larger, more weakly coordinating, counterion facilitated the series to be operable in a more expansive array of solvent media beyond that which had already been reported. A series of ethereal, alcoholic, ester, chlorinated, and aromatic solvents were shown to be applicable, with the more soluble $\mathrm{BAr}_{\mathrm{F}}$ analogue outperforming the $\mathrm{PF}_{6}$ variant in all of the newly established media, as well as offering comparable levels of deuteration to already effective systems. Whilst some variability was observed across a range of alcohol and ester solvents, more hindered such solvent species, such as $t$-AmOH and $i$-PrOAc, performed very well. Additionally, a stark difference was observed in toluene, whereby $\mathrm{BAr}_{F}$ complex 10b 
proved almost twice as effective in the labelling of standard substrate acetophenone over parent complex $\mathbf{4 b}$. Notably, the utility of this improved solvent scope was demonstrated through widely enriched global deuterium labelling of the drug molecule niclosamide 5 in 2MeTHF (Scheme 9).

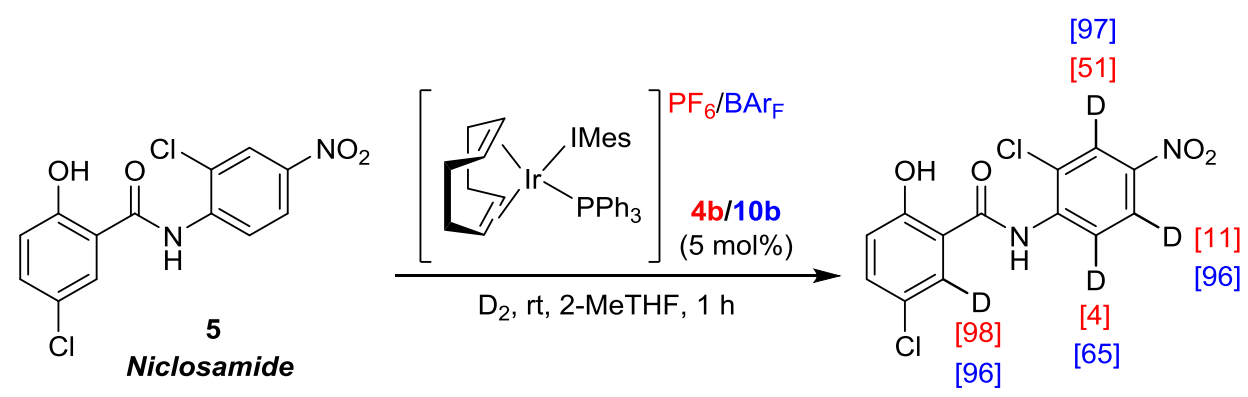

Scheme 9: Deuteration of Niclosamide in 2-MeTHF.

Our studies were extended to include a specific comparison of catalyst $\mathbf{4 b}$, bearing the $\mathrm{Ph}_{3} \mathrm{P} / \mathrm{IMes}$ and $\mathrm{PF}_{6}$ counterion combination, with the equivalent catalyst $10 \mathrm{~b}$, possessing the bulky, less coordinating $\mathrm{BAr}_{\mathrm{F}}$ unit across a range of substrates. ${ }^{24}$ In $\mathrm{DCM}$ both catalysts performed equally well with substrates bearing ketone, ester, amide, and nitro directing groups (DGs) giving near quantitative incorporations at $5 \mathrm{~mol} \%$ loading and under mild conditions. During these studies it was, however, observed that substrates containing two contending directing groups revealed solvent-dependent variations in the selectivity of labelling (Scheme 10). For example, for the labelling of 4-nitroacetophenone 11 in DCM both complexes exhibited similar selectivity and levels of labelling, with high deuterium incorporation observed adjacent to the ketone DG and, as anticipated, significantly reduced levels ortho to the nitro unit. In THF, whilst a similar regioselectivity pattern was noted, the general level of deuterium incorporation was appreciably reduced, which perhaps indicates the requirement for a more hindered ethereal solvent, such as 2-MeTHF (vide supra). Interestingly, whilst the ketone DG remained dominant in the HIE reaction in toluene, $\mathrm{PF}_{6}$ complex $\mathbf{4 b}$ displayed elevated levels of labelling ortho to the nitro DG, suggesting that the less electrophilic nature of $\mathbf{4 b}$, combined with the weak coordination ability of toluene, allows for efficient binding of both DGs and, thus, for HIE to occur at both sites. Indeed, the use of $10 \mathrm{~b}$ re-established the selectivity of this process in line with this reasoning.

As part of this same study the labelling of the antiandrogen drug, nilutamide 12, was assessed (Scheme 10). ${ }^{24}$ With complex $\mathbf{4 b}$ in DCM, almost quantitative levels of deuterium were incorporated ortho to the, normally weakly directing, nitro DG (via a 5-mmi), alongside a small amount of labelling being directed by the amide moiety through a 6-mmi. However, the use of complex $10 \mathrm{~b}$ showed increased levels of selectivity, almost completely eliminating the 6-mmi labelling pathway.

Overall, these comparison studies have shown that generally higher levels of labelling are achieved with catalyst $\mathbf{1 0 b}$, possessing the less coordinating $\mathrm{BAr}_{\mathrm{F}}$ counterion. Additionally and importantly, these investigations also highlighted that a combination of catalyst counterion, substrate solubility, and associated solvent choice are key considerations in order to deliver requisite levels of site-selective isotope incorporation, and as will be more especially 
the case in more complex drug examples. Complexes $10 \mathrm{~b}$ and $10 \mathrm{c}$, as readily handled and stored solids, are now commercially available from Strem Chemicals.

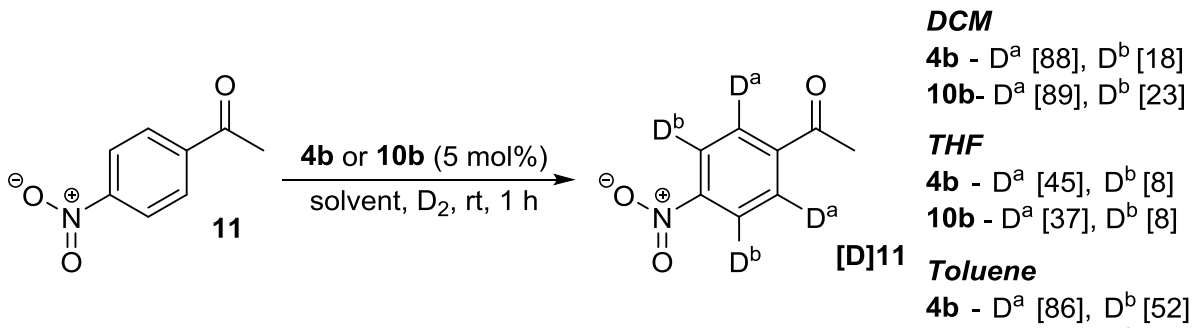

$10 \mathrm{~b}-\mathrm{D}^{\mathrm{a}}[87], \mathrm{D}^{\mathrm{b}}[14]$

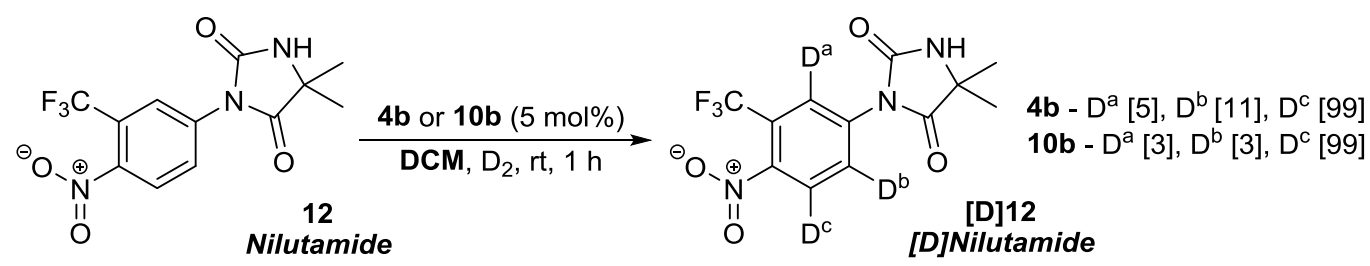

Scheme 10: Comparison of $\mathrm{PF}_{6}$ vs $\mathrm{BAr}_{\mathrm{F}}$ Catalysts.

One particular class of pharmaceutically relevant heterocycles which did not prove amenable to the standard labelling conditions applied in previous examples was the tetrazole unit. Indeed, C-H functionalisations of aryl tetrazoles are rare, with the $\mathrm{N}$-protected analogues often used as starting substrates. ${ }^{25-28}$ Despite this, studies within our laboratory aimed to exploit a different mode of reactivity, involving a concerted metalation-deprotonation (CMD) pathway, in order to utilise unprotected tetrazoles as directing groups for the installation of heavy isotopes of hydrogen. In relation to this, a newly developed, base-assisted, protocol for the use of catalyst $10 \mathrm{~b}$ in the labelling of aryl units possessing free aryl tetrazoles was disclosed in 2016. ${ }^{29}$ Through careful consideration of catalyst, base, temperature, and reaction time, optimised conditions delivering excellent levels of incorporation were achieved across a range of tetrazole-containing substrates (Scheme 11), and which also constituted the first examples of selective $\mathrm{C}-\mathrm{H}$ activation and functionalisation of unprotected tetrazoles. This system was also showcased in the tritium labelling of the antihypertensive drug, valsartan 13. By running the reaction under 212-370 mbar of tritium gas, a sample of this angiotensin receptor blocker was afforded with $15 \mathrm{Ci} / \mathrm{mmol}$ and in excellent radiochemical purity. 


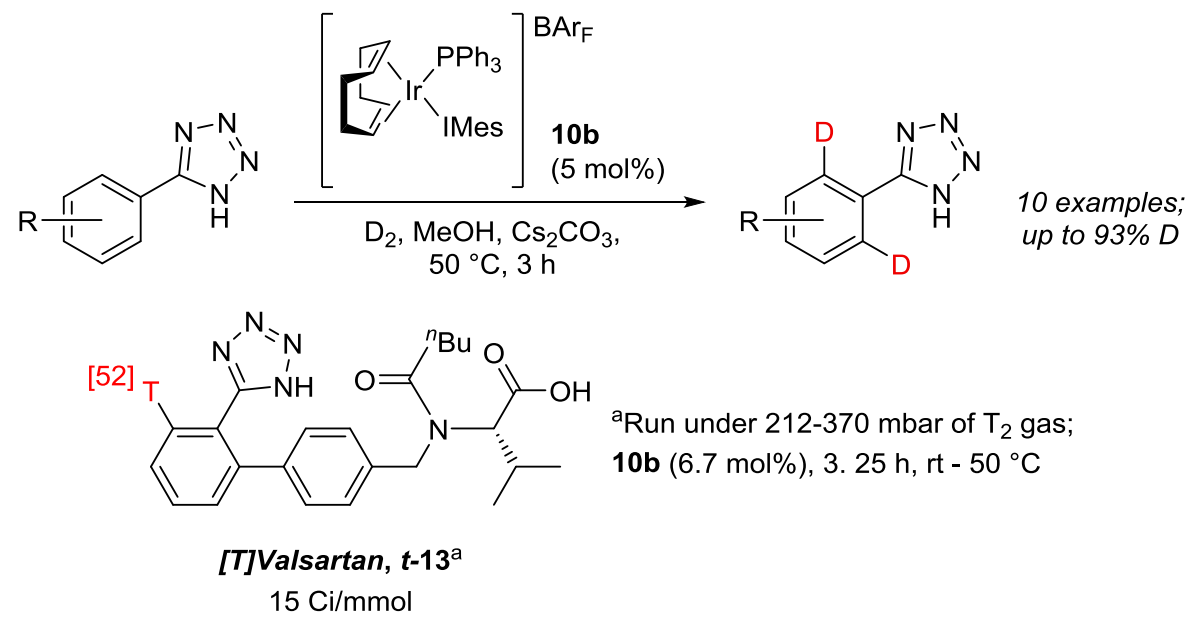

Scheme 11: Base-assisted Labelling of Unprotected Aryl Tetrazoles.

\section{NEUTRAL IRIDIUM SPECIES}

Whilst the established iridium $(\mathrm{I})$ catalysts from our laboratory, bearing both phosphine and $\mathrm{NHC}$ ligands, had shown unprecedented scope in labelling reactions, more challenging motifs had been encountered, which were not accommodated with the required levels of effectiveness by this generation of catalysts. For example, primary sulfonamides, which are prevalent in many drug-type molecules, showed only limited levels of incorporation when using the most active $\mathrm{NHC}$ /phosphine-type catalysts in our library. Accordingly, it was proposed that a catalyst featuring a smaller ligand sphere, and a higher electron density, would favour the accommodation of sulfonamide-containing substrates leading to enhancement in the requisite $\mathrm{C}-\mathrm{H}$ activation step and the subsequent ortho-labelling process. Pleasingly, applying the chlorocarbene complex 14 (a synthetic precursor to the NHC-phosphine catalysts) to $p$ toluenesulfonamide resulted in an impressive $90 \%$ deuterium incorporation, and which represented a substantial increase over the mere $12 \%$ achieved when employing catalyst $4 \mathbf{b}$ (Scheme 12). ${ }^{30}$ These results highlighted the dramatic change in activity which can be achieved by subtle changes in the catalyst parameters.

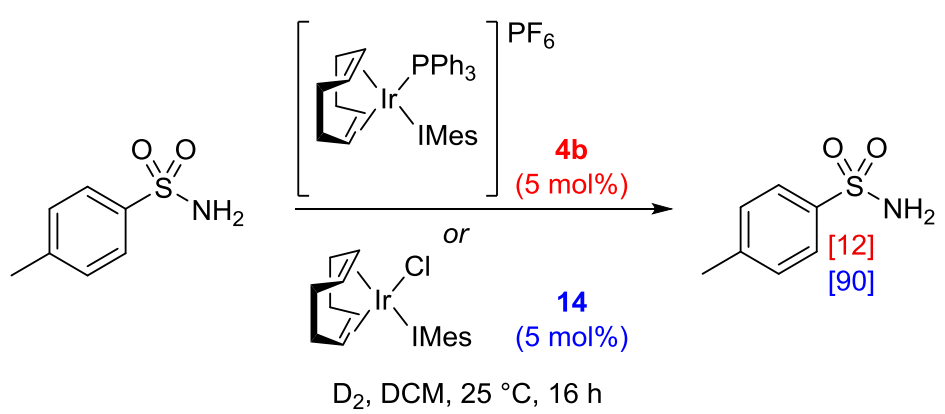

\section{Scheme 12: Labelling of $p$-Toluenesulfonamide.}

In order to optimise these parameters, studies within our laboratory utilised Nolan and Cavallo's Percent Buried Volume $\left(\% \mathrm{~V}_{\text {bur }}\right)^{31}$ and modified Tolman Electronic Parameter $(\mathrm{TEP})^{32,33}$ analyses to explore a number of analogues of catalyst 14 . Overall, complex 15, the most electron-rich of all complexes tested, was established as the optimal species for 
application with primary sulfonamides, facilitating the $\mathrm{C}-\mathrm{H}$ activation and ortho-deuteration of a series of substrates, which required just $2 \mathrm{~h}$ reaction time under readily accessible conditions (Scheme 13). ${ }^{30 a}$ Furthermore, we also established via competition studies the ability of complex 15 to selectively label $p$-toluenesulfonamide in the face of ketone, ester, nitro, and various amide directing groups within separate molecules. Only the $\mathrm{N}$-heterocycles, 1phenylpyrazole and 2-phenylpyridine, were able to compete with 15 to reverse the chemoselectivity of labelling. ${ }^{30 a}$ Having stated this, based on contributing additional (steric and other) factors, it is important to note that this selectivity does not directly translate into multifunctional molecules, i.e. where the competing directing groups are present within the same molecule. For example, when the more complex COX-2 inhibitor, celecoxib 16, possessing both a primary sulfonamide and a pyrazole unit, was applied under the previously optimised conditions with catalyst 15, the direction of labelling favoured deuterium insertion adjacent to the sulfonamide unit, which was in contrast to that recorded in the separate molecule competition and, indeed, reversed the direction of labelling obtained with catalyst $\mathbf{4 b}$ (Scheme 13). ${ }^{30 a}$ Complex 15 is also now available commercially from Strem Chemicals.
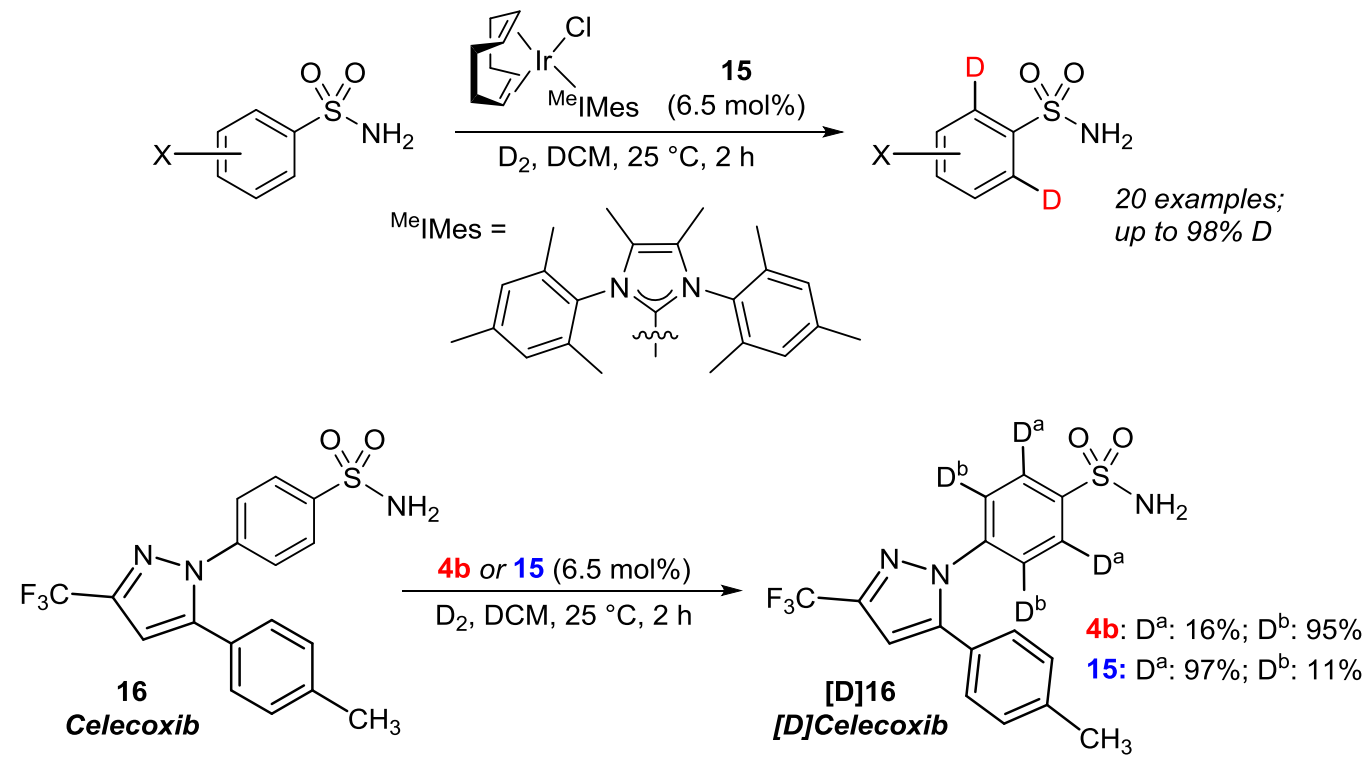

\section{Scheme 13: Optimised Chloro-based Complex for HIE of Primary Sulfonamides.}

This methodology and the associated selectivity observations were underpinned by supporting theoretical studies, with the binding enthalpy $\left(\Delta \mathrm{H}_{\text {bind }}\right)$ and enthalpy of $\mathrm{C}-\mathrm{H}$ insertion $\left(\Delta \mathrm{H}_{\text {ins }}\right)$ calculated in order to support the experimental observations (Scheme 14). ${ }^{30 a}$ Whilst it was found that the binding enthalpy of benzenesulfonamide was more exothermic for the activated form of the cationic, phosphine containing catalysts than the smaller, neutral chloride complex, in contrast to this, the $\mathrm{C}-\mathrm{H}$ activation, predicted to be the rate determining step, was more endothermic for the cationic, phosphine-containing catalyst. Such findings highlight the crucial nature of the catalyst ligand set; indeed, the reduced steric encumbrance of the chlorocarbene system in $\mathbf{1 5}$ relative to the standard phosphine analogue is vital for the successful HIE of primary sulfonamide substrates. 
Complex A: $\mathrm{PPh}_{3}$, IMes

Complex B: $\mathrm{Cl}$, ${ }^{\mathrm{Me}} \mathrm{IMes}$<smiles></smiles>

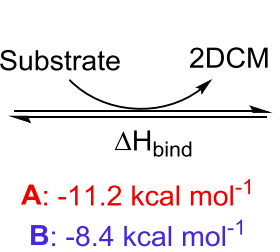

A: $-11.2 \mathrm{kcal} \mathrm{mol}^{-1}$

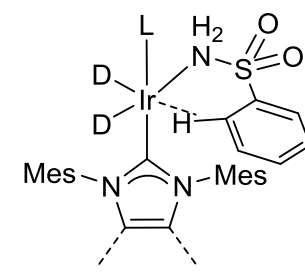
$\mathrm{C}-\mathrm{H}$ Insertion $\Delta \mathrm{H}_{\mathrm{ins}}$
A: $+5.5 \mathrm{kcal} \mathrm{mol}^{-1}$
B: $+3.7 \mathrm{kcal} \mathrm{mol}^{-1}$

\section{Scheme 14: Calculations of Binding and C-H Insertion Energies.}

Shortly following the work just described, the emerging iridium chlorocarbene systems from our laboratory were more fully explored to further showcase their catalytic utility. While many of the catalyst systems discussed thus far have targeted aryl-selective labelling through exploitation of a directing group, the application of the chlorocarbene type catalysts to aryl aldehydes opened a very different mode of reactivity. When these neutral catalyst species are applied, instead of engagement of the aryl $\mathrm{C}-\mathrm{H}$ bonds in close proximity to the aldehyde functionality, it is the formyl $\mathrm{C}-\mathrm{H}$ unit which is preferentially activated and thus labelled. The specific protocol was fully refined in order to tune the selectivity of the catalyst species and the associated process, resulting in complex 17 (Scheme 15). ${ }^{34}$ This novel technique exhibits noteworthy selectivity for the formyl position, ${ }^{35}$ with excellent levels of deuterium being incorporated into an array of aldehyde-containing substrates using only 1-2 mol\% of the optimised catalyst 17. Competing aryl labelling was only detected in a small number of substrates and at low levels in any given case. In order to explain this change in reactivity, an alternate catalytic pathway involving a cis-arrangement of the catalyst ligands (as opposed to the trans-geometry present within mechanistic cycle established with the standard $\mathrm{NHC} /$ phosphine species ${ }^{11 \mathrm{c}}$ ) was proposed and supported by DFT calculations.
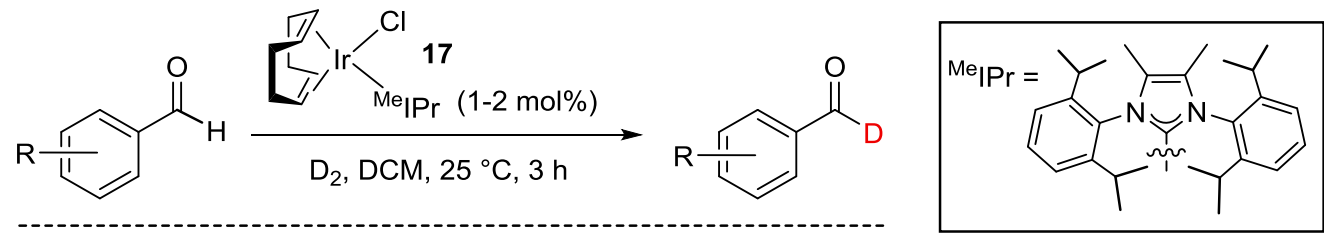<smiles>O=C([18O])c1ccc(C(=O)OC(=O)c2ccccc2)cc1</smiles><smiles>O=C([Hg])c1ccc(Br)cc1</smiles><smiles>O=C(O)c1cccc([N+](=O)[O-])c1</smiles><smiles>O=C([18O])c1ccc(O)cc1</smiles><smiles>Cc1cc(C)cc(C(=O)[18O]c2ccccc2)c1</smiles>

Scheme 15: Labelling at the Formyl Position of Aldehydes.

\section{$\mathrm{C}\left(\mathrm{sp}^{3}\right)$ LABELLING}

With significant advancements in the area of HIE over the last decade having been mainly directed at aryl substrates, we and others have recently focused research towards the, rarer 
and more challenging, activation of $\mathrm{C}\left(\mathrm{sp}^{3}\right)-\mathrm{H}$ bonds. Indeed, the increasing demand for more structurally diverse, $\mathrm{sp}^{3}$-rich, $3 \mathrm{D}$ architectures as potential pharmaceuticals has resulted in endeavours to activate and functionalise such bonds gaining enhanced prominence. In relation to HIE specifically, such methods would provide a complementary labelling pattern for existing substrates, whilst extending methodologies to non-aromatic molecules and those with aromatic portions that cannot currently be readily labelled. Pleasingly, preliminary studies from our laboratory have shown that the highly active $\left[\operatorname{Ir}(\mathrm{COD})\left(\mathrm{PPh}_{3}\right) \mathrm{IMes}\right] \mathrm{BAr}_{\mathrm{F}}$ complex 10b was effective in the $\mathrm{sp}^{3}$ labelling of a range of morpholines, piperidines, and piperazines at low catalyst loadings and under readily accessible conditions, with the label directed by an aza-heterocycle (Scheme 16). ${ }^{36}$ Some of the more challenging (acyclic) examples required a moderate increase in catalyst loading and reaction time, but were, nonetheless, successfully accommodated under comparatively mild conditions. As well as a small number of open chain systems having been applied, the utility of the process was showcased by targeting active pharmaceuticals and other biological active species, including mirtazapine, azaperone, and caffeine, all of which were labelled to $>90 \%$ incorporation at the $\mathrm{sp}^{3}$ site.

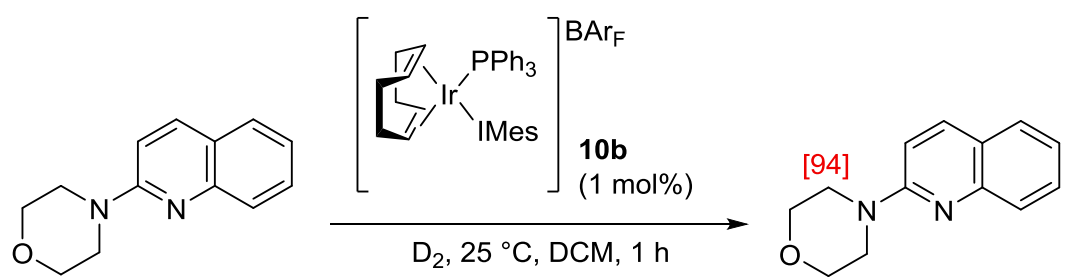

$>20 \mathrm{~N}$-Heterocyclic examples

Conditions: $10 \mathrm{~b}(5 \mathrm{~mol} \%), \mathrm{D}_{2}, 25^{\circ} \mathrm{C}, \mathrm{DCM}, 3 \mathrm{~h}$<smiles>CN(C)c1ccccn1</smiles>

[92]<smiles>CC(C)COc1ccc2ccccc2n1</smiles><smiles>O=C(O)Cc1ccccn1</smiles>

Conditions: $10 \mathrm{~b}(1-5 \mathrm{~mol} \%), \mathrm{D}_{2}, 25^{\circ} \mathrm{C}, \mathrm{DCM}, 1-3 \mathrm{~h}$<smiles>CN1CCCCC1c1ccccc1Cc1cccnc1N1CCCCC1</smiles>

[D]Mirtazapine<smiles>O=C(CCCN1CCCCC1)c1ccc(F)cc1</smiles>

[D]Azaperone<smiles>Cn1c(=O)c2c(ncn2C)n(C)c1=O</smiles>

[D]Caffeine

\section{Scheme 16: Csp³-labelling of Pharmaceutically-relevant Compounds.}

It has also recently been shown by Derdau and co-workers that the same catalyst (10b) is proficient in driving the HIE within aliphatic amide structures, to directly generate labelled amino acid and peptide products (Scheme 17). ${ }^{37}$ The challenging nature of these particular substrates required the more forcing conditions of iso-propyl acetate as the solvent at close to refluxing temperatures. Nonetheless, this catalyst system allowed the efficient labelling of di, tri-, and even tetrapeptide structures. Additionally, it is of note that disulfide structures were tolerated with up to $99 \%$ deuterium incorporation after just $3 \mathrm{~h}$ reaction time. 


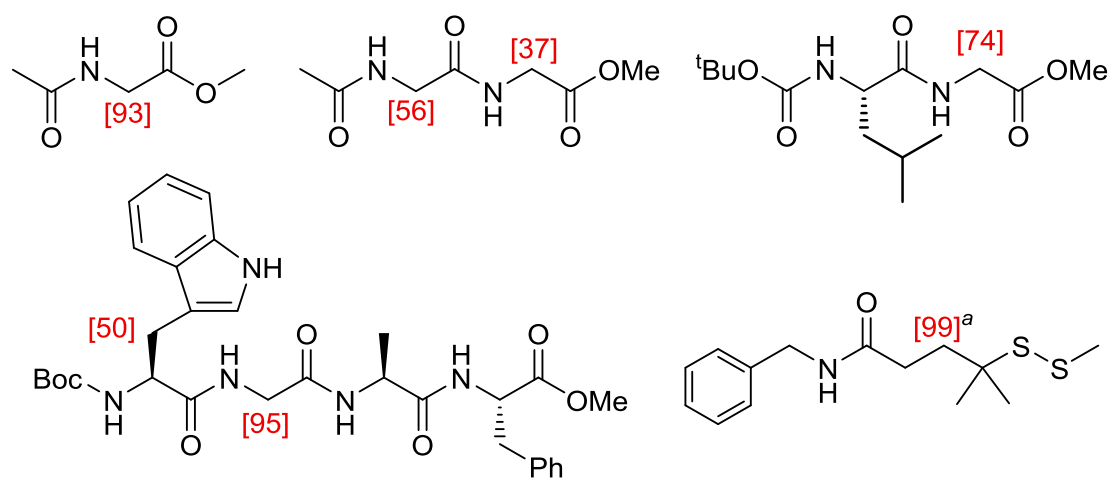

Conditions: $10 \mathrm{~b}(10 \mathrm{~mol} \%)$, $\operatorname{PrOAc}, \mathrm{D}_{2}, 80^{\circ} \mathrm{C}, 8 \mathrm{~h}$; ${ }^{\text {a }} \mathrm{h}$ reaction time

Scheme 17: Labelling of Aliphatic Amide Structures.

\section{BIDENTATE CATALYST SYSTEMS}

Within this developing field of iridium-catalysed hydrogen isotope exchange, it has also emerged that the application of alternative $P, N$-ligated complexes can deliver notable levels of deuteration in a range of substrates. Indeed, from research carried out within own laboratory in relation to the neutral chlorocarbene catalysts (e.g. 14, 15, and 17), it is expected that the cis arrangement of ligands within bidentate species results in electronically and sterically different complexes, which, indeed, could possibly lead to improved systems for HIE. ${ }^{30 a, 34}$

The first example of the use of such bidendate species in HIE was in 2014 with Muri and coworkers disclosing an effective protocol using Pfaltz's PHOX-based ligands, ${ }^{38}$ species that were originally employed within asymmetric hydrogenation processes. Despite the air- and moisture-sensitive nature of such complexes, a range of substrates with both strong directing groups such as pyridines, ketones, and amides, as well as weakly ligating units such as nitro and sulfonamides, were shown to incorporate deuterium at very good levels using only $5 \mathrm{~mol} \%$ of a series of such catalyst species and, in particular, those possessing an electron-rich phosphorus unit, e.g. 18, at room temperature (Scheme 18). Notably, Muri et al. were also able to introduce deuterium ortho to a secondary sulfonamide unit, albeit under more forcing conditions than their standard protocol. Additionally, phenyl methyl sulfone was applied for the first time within such directed HIE procedures, and, with the addition of tris(pentafluorophenyl)borane to the reaction mixture, it was also shown that a normally highly deactivating nitrile substituent could be tolerated. In the same publication, the authors disclosed a more accessible and achiral variant of Pfaltz's original catalysts, again with a requirement for an electron-rich phosphorus moiety, which also proved to be a good catalyst for HIE, providing, generally, comparable results. 


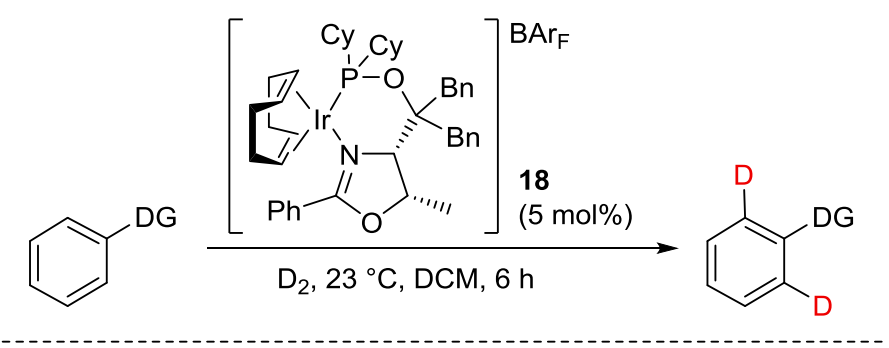<smiles>CC(=O)Nc1ccccc1C(C)=O</smiles><smiles>CNS(=O)(=O)c1ccccc1[AsH2]c1ccccc1</smiles>

${ }^{a} \mathrm{PhCl}, 90^{\circ} \mathrm{C}, 18 \mathrm{~h} ;{ }^{b} 95 \% \mathrm{D}$ with $[\operatorname{lr}(\mathrm{COD}) \mathrm{NeoPHOX}] \mathrm{BAr}_{\mathrm{F}}$

\section{Scheme 18: HIE Using Pfaltz's Catalyst.}

Isotope chemists at Sanofi-Aventis in Frankfurt, Germany have identified that hydrogenation catalyst 19, developed by Burgess, ${ }^{39}$ can be applied in HIE with varying levels of efficiency. ${ }^{40}$ It was illustrated that this commercial and air-stable catalyst facilitated the selective orthodeuteration of secondary and tertiary sulfonamides, and sulfonyl ureas, allowing, normally, less accessible deuterated products to be obtained at, up to, appreciable levels of incorporation, albeit at elevated temperatures in chlorobenzene. The authors noted that a similar reactivity was observed when applying Kerr's strategies with [(COD)Ir(IMes)Cl] complex 14 at $10 \mathrm{~mol} \%$ under similarly forcing conditions, with this catalyst 14 typically proving most efficient in labelling secondary sulfonamides and sulfonyl ureas, and the Burgess catalyst 19 delivering the highest levels of deuterium incorporation for tertiary sulfonamides (Scheme 19). ${ }^{40}$ Interestingly, there was no deuterium delivered through a 6-mmi, for example in the $\mathrm{N}$ phenyl sulfonamide substrates, highlighting the challenge of accessing such an intermediate with these directing groups. In this same publication, the authors also extended their scope to include the deuterium labelling of a series of sulfa drugs, as well as adapting the conditions to allow for selective tritium labelling. 


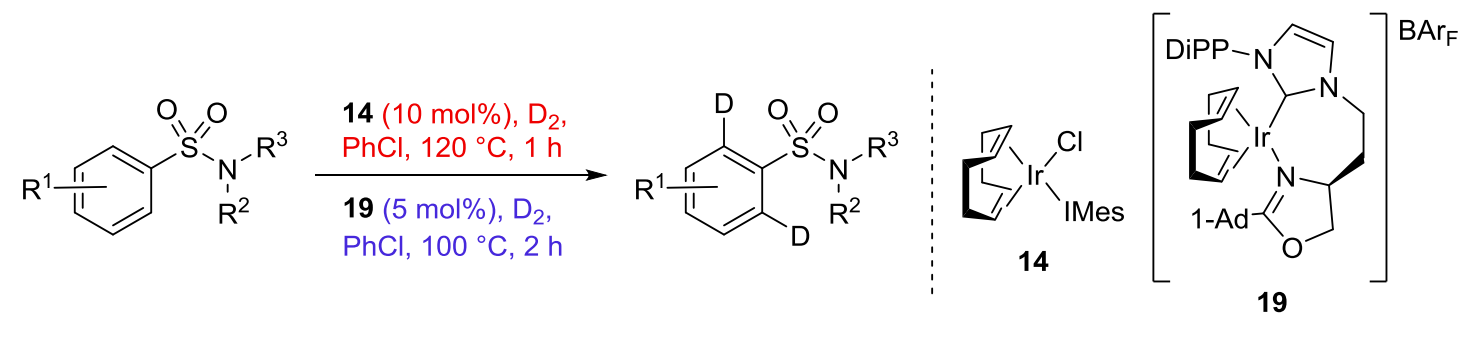<smiles>O=S(=O)(Nc1ccccc1)c1ccccc1</smiles><smiles>CS(=O)(=O)Nc1ccccc1</smiles><smiles>Cc1ccccc1S(=O)(=O)NCCN(C)C</smiles><smiles>CN(C)S(=O)(=O)c1cccc2cccc([N+](=O)[O-])c12</smiles><smiles>O=C(O[Ga])C1CCCCN1S(=O)(=O)c1ccccc1</smiles><smiles>CCCNC(=O)NS(=O)(=O)c1ccc(Cl)cc1</smiles><smiles>Cc1cc(NS(=O)(=O)c2ccc(N)cc2)no1</smiles>

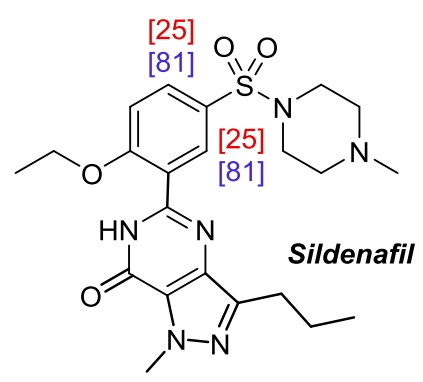

\section{Scheme 19: Chloro-based Complex 14 vs Burgess' Catalyst 19 for HIE of $2 y$ and $3 y$ Sulfonamides and Sulfonylureas.}

In a following publication the same year, the same researchers fully evaluated the use of the Burgess iridium(I)-catalyst 19 , which proved competent in labelling a series of common functional groups, this time under ambient reaction conditions at $10 \mathrm{~mol} \%{ }^{41}$ Ketones, aldehydes, amides (via both a 5- and 6-mmi), pyridines, and nitro directing groups were labelled at good to excellent levels. Interestingly, sulfur-based directing groups were shown to label to moderate levels under these milder conditions.

Inspired by the results from Muri et al., a collaborative study between the Sanofi laboratories and Tamm and co-workers recently evaluated the use of Tamm's bidentate NHC-P complex 20 in HIE reactions. ${ }^{42}$ This highly electron-rich ligand set facilitates the labelling of a wide range of directing groups to high levels (Scheme 20); while ketones, heterocycles, the nitro group, and esters were shown to be suitable, perhaps the most noteworthy results were those which employed a Boc unit to direct labelling into the aryl rings of anilines or heterocycles. ${ }^{42 a}$ The significant steric bulk of this Boc protecting group may usually render its use challenging; however, the chelated system present within Tamm's catalyst allows for excellent levels of incorporation under mild conditions. Furthermore, this system now also allows for $97 \%$ deuterium incorporation in phenyl methyl sulfone, and, at least as interestingly, in the absence of any competing directing groups, the benzylamine and methoxy motifs have shown directing group ability. 

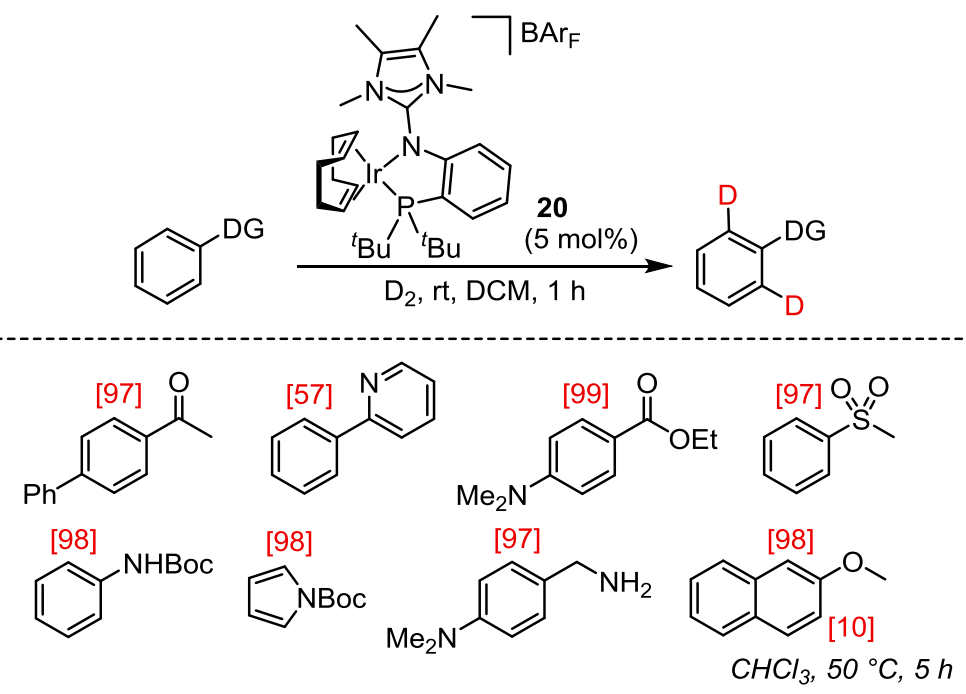

Scheme 20: Evaluation of Tamm's Bidentate Catalyst.

Sanofi's isotope chemists, alongside Tamm and co-workers, also established the ability of the same catalyst $(\mathbf{2 0})$ to label highly hindered sulfonamides, $\mathrm{N}$-oxides, and phosphonamides (Scheme 21). ${ }^{42 b}$ Unlike previous attempts to label hindered sulfonamides with chlorocarbene catalyst 14, or, indeed, the Pfaltz and Burgess systems, the Tamm catalyst affords much higher levels of incorporation into $N$-substituted and $N, N$-disubstituted sulfonamides under appreciably more mild conditions.<smiles>CCN(CC)S(=O)(=O)c1ccc(Cl)cc1</smiles><smiles>[O-][n+]1ccc2ccccc2c1</smiles>

[93]<smiles>O=P(c1ccccc1)(N1CCCCC1)N1CCCCC1</smiles>

Conditions: 20 (10 mol\%), $\mathrm{D}_{2}, \mathrm{rt}, \mathrm{PhCl}, 2 \mathrm{~h}$

\section{Scheme 21: Further Notable Examples Using Catalyst 20.}

Finally, and in a very recent addition to the use of bidentate iridium(I) complexes in HIE processes, Tamm and Derdau have established a catalytic protocol for the selective labelling of pharmacologically important phenylacetic acid esters and amides under mild reaction conditions. ${ }^{43}$ Employing Tamm's $P, N$-ligated complex 20, >25 substrates have been labelled, via the more challenging 6-mmi, with deuterium incorporation up to $99 \%$. The authors have also adapted this method to the requirements of tritiation chemistry, and demonstrated the direct tritiation of the fungicide, benalaxyl, amongst other pharmaceutical compounds (Scheme 22). 


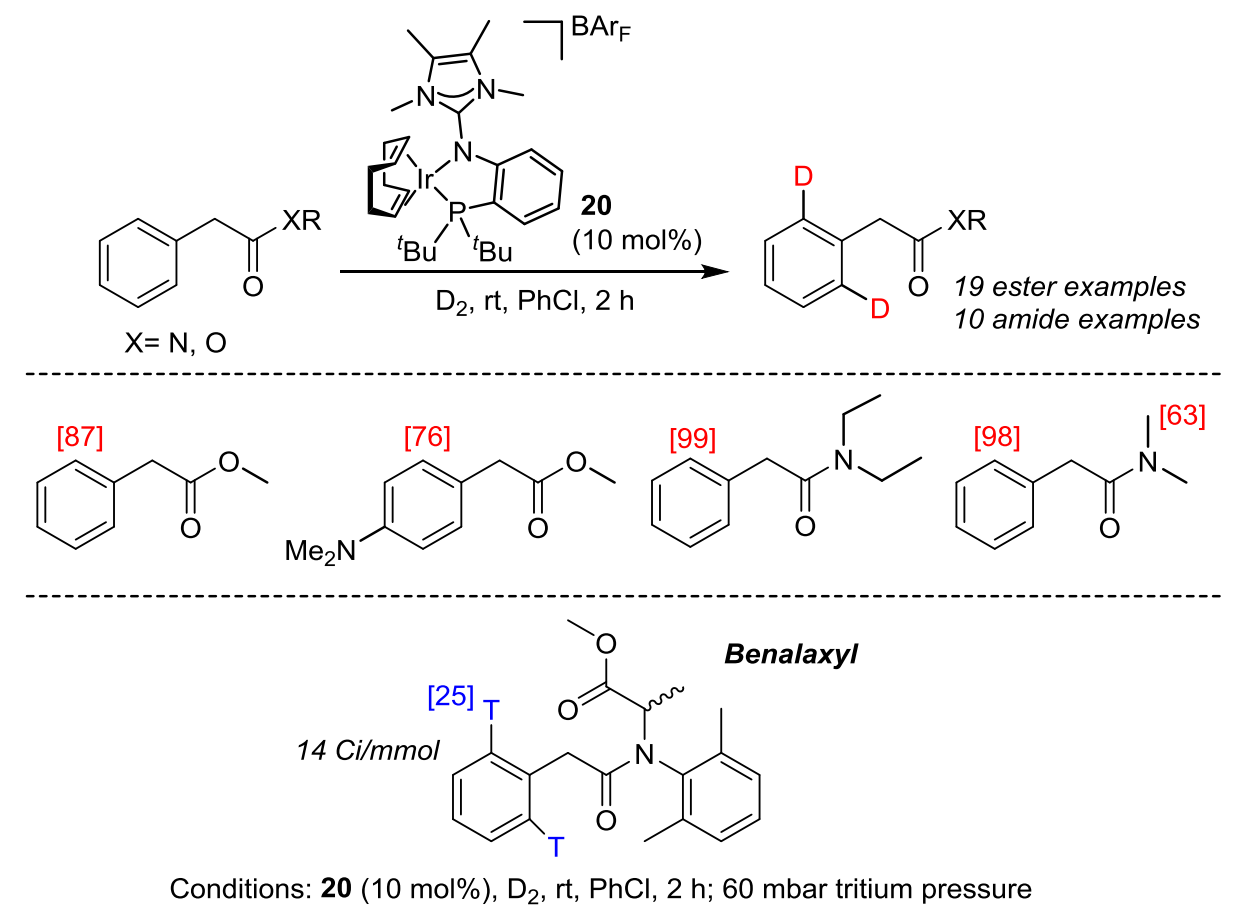

Scheme 22: HIE of Phenylacetic Acid Esters and Amides.

\section{CONCLUSIONS}

Isotopically labelled compounds form an essential part of drug discovery and development, particularly within the pharmaceutical industry, and direct methods such as ortho-directed C$\mathrm{H}$ activation and functionalisation using homogeneous catalysis has introduced a step-change in the ability to label pharmaceutical candidate molecules with radioactive (tritium) or nonradioactive (deuterium) isotopes. Following the emergence of iridium(l) $\mathrm{NHC}$ /phosphinebased catalysts from our laboratory, species which are capable of incorporating high levels of deuterium (and tritium) to aromatic molecules under mild and efficient reaction manifolds, the field of iridium catalysis for HIE has been further and extensively diversified in terms of catalyst structure, key substrate scope, and mode of labelling. The methods described in this review highlight the appreciable range of new and highly active iridium $(\mathrm{I})$ catalysts that have been developed over the last decade for broadened application within novel $\mathrm{C}-\mathrm{H}$ activation and hydrogen isotope exchange processes.

Importantly, close collaborations between industry scientists and academic researchers have allowed strategic developments whereby substrate and synthetic target focus has guided and motivated catalyst design and application to very effectively create alignment with the requirements and goals of pharmaceutical partners and programmes. It is clear that research to broaden the applicable directing groups and functionality amenable to selective labelling protocols remains highly pertinent and vibrant. Specifically, a wider range of aromatic systems containing ketones, amides, esters, nitroarenes, an array of heterocycles, and various nonaromatic unsaturated functionalities can be labelled under mild conditions, and, importantly, now in an array of solvents, in particular, using the $\mathrm{BAr}_{\mathrm{F}}$ analogues of first generation catalysts. Furthermore, new catalyst systems, such as neutral chlorocarbene systems and $P, N$-ligated catalysts, have emerged as extremely effective species for installing key isotopes of hydrogen 
into new and previously inapplicable substrate classes, including sulfonamides, sulfones, and the formyl position of aryl aldehydes. Additionally, labelling into rarer, and more challenging, C-sp ${ }^{3}$ hybridised centres has also started to emerge.

The development of such systems, as described herein, have had direct impact within the laboratories of pharmaceutical partners, with the labelling of a range of drug molecules having been reported alongside catalyst and method development. In many of these cases, only low (and generally less than $10 \mathrm{~mol} \%$ ) catalyst loadings are required, with ambient temperatures and gas pressures more than often sufficient to obtain the desired levels of labelling.

From more recent studies, it has also become clear that the application of computational methods combined with experimental mechanistic investigations and kinetic studies are beginning to form a core component of this particular area of research. In a number of recent examples, such approaches have led to a more comprehensive understanding of the emerging catalyst species and, in turn, have directly informed catalyst design. As catalyst researchers and their pharmaceutical partners continue to strive to incorporate isotopic labels guided by an increasingly broadened array of functional units and within molecular frameworks of heightened complexity, and all with escalating levels of site selectivity, such blended theoretical, spectroscopic, and experimental strategies will become increasingly important in order to drive the design of catalysts for further enhanced, next generation HIE processes.

\section{REFERENCES}

[1] For reviews on hydrogen isotope exchange, see: a) Atzrodt J, Derdau V, Fey $\mathrm{T}$, Zimmermann J. The Renaissance of H/D Exchange. Angew Chem Int Ed. 2007;46:77447765. b) Allen PH, Hickey MJ, Kingston LP, Wilkinson DJ. Metal-Catalysed Isotopic Exchange Labelling: 30 Years of Experience in Pharmaceutical R\&D. J Label Compd Radiopharm. 2010;53:731-738. c) Atzrodt J, Derdau V, Kerr WJ, Reid M. C-H Functionalisation for Hydrogen Isotope Exchange. Angew Chem Int Ed. 2018;57:3022-3047.

[2] Lockley WJS. 30 Years with ortho-Directed Hydrogen Isotope Exchange Labelling. J Label Compd Radiopharm. 2007;50:779-788.

[3] a) Isin EM, Elmore CS, Nilsson GN, Thompson RA, Weidolf L. Use of Radiolabeled Compounds in Drug Metabolism and Pharmacokinetic Studies. Chem Res Toxicol. 2012;25:532-542. b) Lockley WJS, McEwen A, Cooke R. Tritium: A Coming of Age for Drug Discovery and Development ADME Studies. J Label Compd Radiopharm. 2012;55:235-257. c) Atzrodt J, Derdau V, Kerr WJ, Reid M. Deuterium- and Tritium-Labelled Compounds: Applications in the Life Sciences. Angew Chem Int Ed. 2018;57:1758-1784.

[4] For selected homogeneous catalysis examples, see: a) Garnett JL, Hodges RJ. Homogeneous Metal-Catalyzed Exchange of Aromatic Compounds. A New General Isotopic Hydrogen Labeling Procedure. J Am Chem Soc. 1967;89:4546-4547. b) Hickman AJ, Villalobos JM, Sanford MS. Quantitative Assay for the Direct Comparison of Platinum Catalysts in Benzene H/D Exchange. Organometallics 2009;28:5316-5322. c) Emmert MH, Gary JB, Villalobos JM, Sanford MS. Platinum and Palladium Complexes Containing Cationic Ligands as Catalysts for Arene H/D Exchange and Oxidation. Angew Chem Int Ed. 2010;49:5884-5886.

[5] For selected homogeneous catalysis examples, see: a) Blake MR, Garnett JL, Gregor IK, Hannan W, Hoa K, Long MA. Rhodium Trichloride as a Homogeneous Catalyst for Isotopic 
Hydrogen Isotope Exchange. Comparison with Heterogeneous Rhodium in the Deuteration of Aromatic Compounds and Alkanes. J Chem Soc Chem Commun. 1975;(23):930-932.

b) Lockley WJS. Regioselective Deuteration of Aromatic and $\alpha, \beta-$-Unsaturated Carboxylic Acids via Rhodium(III) Chloride Catalysed Exchange with Deuterium Oxide. Tetrahedron Lett. 1982;23:3819-3822. c) Hesk D, Jones JR, Lockley WJS. Regiospecific Deuteriation and Tritiation of Various Drugs Using a Homogeneous Rhodium Trichloride Catalyst. J Pharm Sci. 1991;80:887-890.

[6] For a recent example, see: Gao L, Perato S, Garcia-Argote S, Taglang C, Martínez-Prieto LM, Chollet C, Buisson D-A, Dauvois V, Lesot P, Chaudret B, Rousseau B, Feuillastre S, Pieters G. Ruthenium-Catalyzed Hydrogen Isotope Exchange of $\mathrm{C}\left(\mathrm{sp}^{3}\right)-\mathrm{H}$ Bonds Directed by a Sulfur Atom. Chem Commun. 2018;54:2986-2989. For a recent review on Rh and Ru HIE methods, see: Lockley WJS, Hesk D. Rhodium- and Ruthenium-Catalysed Hydrogen Isotope Exchange. J Label Compd Radiopharm. 2010;53:704-715.

[7] a) Heys JR. Organoiridium Complexes for Hydrogen Isotope Exchange Labeling. $J$ Label Compd Radiopharm. 2007;50:770-778. b) Salter R. The Development and Use of Iridium(I) Phosphine Systems for ortho-Directed Hydrogen Isotope Exchange. J Label Compd Radiopharm. 2010;53:645-657. c) Lockley WJS. Hydrogen Isotope Labelling Using Iridium(I) Dionates. J Label Compd Radiopharm. 2010;53:668-673.

[8] Crabtree R. Iridium Compounds in Catalysis. Acc Chem Res. 1979;12:331-337.

[9] a) Hesk D, Das PR, Evans D. Deuteration of Acetanilides and Other Substituted Aromatics using $\left[\operatorname{Ir}(\mathrm{COD})\left(\mathrm{Cy}_{3} \mathrm{P}\right)(\mathrm{Py})\right] \mathrm{PF}_{6}$ as Catalyst. J Label Compd Radiopharm. 1995;36:497-502; b) Shu AYL, Chen W, Heys JM. Organoiridium Catalyzed Hydrogen Isotope Exchange: Ligand Effects on Catalyst Activity and Regioselectivity. J Organomet Chem. 1996;524:87-93.

[10] Ellames GJ, Gibson JS, Herbert JM, McNeill AH. The Scope and Limitations of Deuteration Mediated by Crabtree's Catalyst. Tetrahedron 2001;57:9487-9497.

[11] a) Brown JA, Irivne S, Kennedy AR, Kerr WJ, Andersson S, Nilsson GN. Highly Active Iridium(I) Complexes for Catalytic Hydrogen Isotope Exchange. Chem Commun. 2008;(9):1115-1117. b) Nilsson GN, Kerr WJ. The Development and Use of Novel Iridium Complexes as Catalysts for ortho-Directed Hydrogen Isotope Exchange Reactions. J Label Compd Radiopharm. 2010;53:662-667. c) Brown, JA, Cochrane AR, Irvine S, Kerr WJ, Mondal B, Parkinson JA, Paterson LC, Reid M, Tuttle T, Andersson S, Nilsson GN. The Synthesis of Highly Active Iridium(I) Complexes and their Application in Catalytic Hydrogen Isotope Exchange. Adv Synth Catal. 2014;356:3551-3562.

[12] Cochrane AR, Idziak C, Kerr WJ, Mondal B, Paterson LC, Tuttle T, Andersson S, Nillson GN. Practically Convenient and Industrially-Aligned Methods for Iridium-Catalysed Hydrogen Isotope Exchange Processes. Org Biomol Chem. 2014;12:3598-3603.

[13] Atzrodt J, Derdau V, Kerr WJ, Reid M, Rojahn P, Weck R. Expanded Applicability of Iridium(I) NHC/Phosphine Catalysts in Hydrogen Isotope Exchange Processes with Pharmaceutically-Relevant Heterocycles. Tetrahedron 2015;71:1924-1929.

[14] Kerr WJ, Lindsay DM, Owens PK, Reid M, Tuttle T, Campos S. Site-Selective Deuteration of $\mathrm{N}$-Heterocycles via Iridium-Catalyzed Hydrogen Isotope Exchange. ACS Catal. 2017;7:7182-7186.

[15] Devlin J, Kerr WJ, Lindsay DM, McCabe TJD, Reid M, Tuttle T. Iridium-Catalysed orthoDirected Deuterium Labelling of Aromatic Esters - An Experimental and Theoretical Study on Directing Group Chemoselectivity. Molecules 2015;20:11676-11698.

[16] Kerr WJ, Mudd RJ, Paterson LC, Brown JA. Iridium(I)-Catalyzed Regioselective C-H Activation and Hydrogen-Isotope Exchange of Non-aromatic Unsaturated Functionality. Chem Eur J. 2014;20:14604-14607. 
[17] Simonsson R, Stenhagen G, Ericsson C, Elmore CS. Synthesis of Ximelagatran, Melagatran, Hydroxymelagatran, and Ethylmelagatran in H-3 Labeled Form. J Label Compd Radiopharm. 2013;56:334-337.

[18] Allen P, Bragg RA, Caffrey M, Ericsson C, Hickey MJ, Kingston LP, Elmore CS. The Synthesis of a Tritium, Carbon-14, and Stable Isotope-Labeled Cathepsin C Inhibitors. J Label Compd Radiopharm. 2017;60:124-129.

[19] a) Elmore CS, Hall JE, Ye X, Heys JR. Synthesis of Two Isotopically Labeled 5-HT 1 B Antagonists. J Label Compd Radiopharm. 2007;50:412-413. b) Lindelöf A, Ericsson C, Simonsson R, Nilsson G, Grönberg G, Elmore CS. Synthesis of $\left[{ }^{3} \mathrm{H}\right]$ and $\left[{ }^{2} \mathrm{H}_{6}\right] A Z D 6642$, an Inhibitor of 5-Lipoxygenase Activating Protein (FLAP). J Label Compd Radiopharm. 2016;59; 340-345.

[20] Flinker M, Yin H, Juhl RW, Eikeland EZ, Overgaard J, Nielsen DU, Skrydstrup T. Efficient Water Reduction with $\mathrm{sp}^{3}-\mathrm{sp}^{3}$ Diboron(4) Compounds: Application to Hydrogenations, H-D Exchange Reactions, and Carbonyl Reductions. Angew Chem Int Ed. 2017;56:15910-15915. [21] Modvig A, Andersen TL, Taaning RH, Lindhardt AT, Skrydstrup T. Two-Chamber Hydrogen Generation and Application: Access to Pressurized Deuterium Gas. J Org Chem. 2014;79:5861-5868.

[22] Kennedy AR, Kerr WJ, Moir R, Reid M. Anion Effects to Deliver Enhanced Iridium Catalysts for Hydrogen Isotope Exchange Processes. Org Biomol Chem. 2014;12:7927-7931. [23] a) Lightfoot A, Schnider P, Pfaltz A. Enantioselective Hydrogenation of Olefins with Iridium-Phosphanodihydrooxazole Catalysts. Angew Chem Int Ed. 1998;37:2897-2899. b) Smidt SP, Zimmermann N, Studer M, Pfaltz A. Enantioselective Hydrogenation of Alkenes with Iridium-PHOX Catalysts: A Kinetic Study of Anion Effects. Chem Eur J. 2004;10:46854693. c) Vazquez-Serrano LD, Owens BT, Buriak JM. The Search for New Hydrogenation Catalyst Motifs Based on N-Heterocyclic Carbene Ligands. Inorg Chim Acta. 2006;359:27862797. d) Nelson DJ, Truscott BJ, Egbert JD, Nolan SP. Exploring the Limits of Catalytic Ammonia-Borane Dehydrogenation Using a $\mathrm{Bis}(\mathrm{N}$-Heterocyclic Carbene) Iridium(III) Complex. Organometallics. 2013;32:3769-3772.

[24] Kerr WJ, Mudd RJ, Owens PK, Reid M, Brown JA, Campos S. Hydrogen Isotope Exchange with Highly Active Iridium(I) NHC/Phosphine Complexes: A Comparative Counterion Study. J Label Compd Radiopharm. 2016;59:601-603.

[25] a) Matsuura Y, Tamura M, Kochi T, Sato M, Chatani N, Kakiuchi F. The Ru(cod)(cot)Catalyzed Alkenylation of Aromatic C-H Bonds with Alkenyl Acetates. J Am Chem Soc. 2007;129:9858-9859. b) Sadhu P, Alla SK, Punniyamurthy T. Pd(II)-Catalyzed Aminotetrazole-Directed ortho-Selective Halogenation of Arenes. J Org Chem. 2013;78:61046111.

[26] a) Wang L, Wu W, Chen Q, He M. Rhodium-Catalyzed Olefination of Aryl Tetrazoles via Direct C-H Bond Activation. Org Biomol Chem. 2014;12:7923-7926. b) Li J, Ackermann L. Cobalt-Catalyzed $\mathrm{C}-\mathrm{H}$ Arylations with Weakly-Coordinating Amides and Tetrazoles: Expedient Route to Angiotensin-II-Receptor Blockers. Chem Eur J. 2015;21:5718-5722.

[27] For the $\mathrm{C}-\mathrm{H}$ activation of a protected $2 \mathrm{H}$-tetrazole, see: Chen $\mathrm{B}$, Jiang $\mathrm{Y}$, Cheng J, Yu JT. Rhodium-Catalyzed Hydroarylation of Alkynes via Tetrazole-Directed C-H Activation. Org Biomol Chem. 2015;13:2901-2904.

[28] Gribble GW, in Science of Synthesis, Organometallics, ed. Majewski M, Snieckus V, Thieme, Stuttgart, 2006;8a:372-373.

[29] Kerr WJ, Lindsay DM, Reid M, Atzrodt J, Derdau V, Rojahn P, Weck R. Iridium-Catalyzed ortho-H/D and -H/T Exchange Under Basic Conditions: C-H Activation of Unprotected Tetrazoles. Chem Commun. 2016;52:6669-6672. 
[30] a) Kerr WJ, Reid M, Tuttle T. Iridium-Catalyzed C-H Activation and Deuteration of Primary Sulfonamides: An Experimental and Computational Study. ACS Catal. 2015;5:402-410. See also b) Cochrane AR, Irvine S, Kerr WJ, Reid M, Andersson S, Nilsson GN. Application of Neutral Iridium(I) $\mathrm{N}$-Heterocyclic Carbene Complexes in ortho-Directed Hydrogen Isotope Exchange. J Label Compd Radiopharm. 2013;56:451-454.

[31] a) Poater A, Cosenza B, Correa A, Giudice S, Ragone F, Scarano V, Cavallo L. Samb Vca: A Web Application for the Calculation of the Buried Volume of $\mathrm{N}$-Heterocyclic Carbene Ligands. Eur J Inorg Chem. 2009;(13):1759-1766. b) Clavier H, Nolan SP. Percent Buried Volume for Phosphine and $\mathrm{N}$-Heterocyclic Carbene Ligands: Steric Properties in Organometallic Chemistry. Chem Commun. 2010;46:841-861.

[32] Kelly III RA, Clavier H, Giudice S, Scott NM, Stevens ED, Bordner J, Samardjiev I, Hoff $\mathrm{CD}$, Cavallo L, Nolan SP. Determination of $\mathrm{N}$-Heterocyclic Carbene (NHC) Steric and Electronic Parameters using the $\left[(\mathrm{NHC}) \operatorname{lr}(\mathrm{CO})_{2} \mathrm{Cl}\right]$ System. Organometallics 2008;27:202-210.

[33] For reviews on NHC electronics, see: a) Dröge T, Glorius F. The Measure of all Rings $\mathrm{N}$-Heterocyclic Carbenes. Angew Chem Int Ed. 2010;49:6940-6952. b) Nelson DJ, Nolan SP. Quantifying and Understanding the Electronic Properties of $\mathrm{N}$-Heterocyclic Carbenes. Chem Soc Rev. 2013;42:6723-6753.

[34] Kerr WJ, Reid M, Tuttle T. Iridium-Catalyzed Formyl-Selective Deuteration of Aldehydes. Angew Chem Int Ed. 2017;56:7808-7812.

[35] Other cases of such catalysed HIE at the formyl position have been divulged, albeit without formyl unit labelling selectivity, which arises from accompanied aryl labelling; for examples, see: a) Chappelle MR, Morgan AD, Tomkinson NCO, Willson TM. Tritium Labeling of the PXR Ligand GW5801 - An Unexpected Tritium Exchange Reaction. Synth Appl Isotop Lab Comp. Proceedings of the $7^{\text {th }}$ International Symposium, Eds: Pleiss U, Roges R. Wiley, New York. 2001:80-83. b) Chappelle MR, Hawes CR. The Use of Metal-Catalysed Hydrogen Isotope Exchange in the Contract Supply of Tritiated Compounds. J Label Compd Radiopharm. 2010;53:745-751. c) Skaddan, MB, Yung, CM, Bergman, RG. Stoichiometric and Catalytic Deuterium and Tritium Labeling of "Unactivated" Organic Substrates with Cationic Ir(III) Complexes. Org Lett. 2004;6:11-13.

[36] Kerr WJ, Mudd RJ, Reid M, Atzrodt J, Derdau V. Iridium-Catalysed Csp ${ }^{3}-\mathrm{H}$ Activation for Mild and Selective Hydrogen Isotope Exchange. ACS Catal. 2018;8:10895-10900.

[37] Valero M, Weck R, Güssregen S, Atzrodt J, Derdau V. Highly Selective Directed IridiumCatalyzed Hydrogen Isotope Exchange Reactions of Aliphatic Amides. Angew Chem Int Ed. 2018;57:8159-8163.

[38] Parmentier M, Hartung T, Pfaltz A, Muri D. Iridium-Catalysed H/D Exchange: Ligand Complexes with Improved Efficiency and Scope. Chem Eur J., 2014;20:11496-11504.

[39] Perry MC, Cui X, Powell MT, Hou D-R, Reibenspies JH, Burgess K. Optically Active Iridium Imidazol-2-ylidene-oxazoline Complexes: Preparation and Use in Asymmetric Hydrogenation of Arylalkenes. J Am Chem Soc. 2003;125:113-123.

[40] Burhop A, Weck R, Atzrodt J, Derdau V. Hydrogen-Isotope Exchange (HIE) Reactions of Secondary and Tertiary Sulfonamides and Sulfonylureas with Iridium(I) Catalysts. Eur J Org Chem. 2017;(11):1418-1424.

[41] Burhop A, Prohaska R, Weck R, Atzrodt J, Derdau V. Burgess Iridium(I)-Catalyst for Selective Hydrogen Isotope Exchange. J Label Compd Radiopharm. 2017;60:343-348.

[42] a) Jess K, Derdau V, Weck R, Atzrodt J, Freytag M, Jones PG, Tamm M. Hydrogen Isotope Exchange with Iridium(I) Complexes Supported by Phosphine-Imidazolin-2-imine $P, N$ 
Ligands. Adv Synth Catal. 2017;359:629-638. b) Valero M, Burhop A, Jess K, Weck R, Tamm $\mathrm{M}$, Atzrodt J, Derdau V. Evaluation of a $P, N$-ligated Iridium(I) Catalyst in Hydrogen Isotope Exchange Reactions of Aryl and Heteroaryl Compounds. J Label Compd Radiopharm. 2018;61:380-385.

[43] Valero M, Becker D, Jess K, Weck R, Atzrodt J, Bannenberg T, Derdau V, Tamm M. Directed Iridium-Catalyzed Hydrogen Isotope Exchange Reactions of Phenylacetic Acid Esters and Amides. Chem Eur J. 2019;25:6517-6522. 